\title{
Anatomia e terapia da mente humana: o De intellectus emendatione de Espinosa
}

\author{
Marilena Chaui \\ Universidade de São Paulo (USP)
}

\section{RESUMO}

$\mathrm{O}$ artigo busca reavaliar a tradição interpretativa do Tratactus de Intellectus Emendatione, propondo uma outra maneira de ler a primeira obra de Espinosa.

\section{PALAVRAS-CHAVE}

Espinosa;

Tratactus de Intellectus Emendatione;

Filosofia moderna.

\section{ABSTRACT}

The article seeks to reevaluate the interpretative tradition of the Intellectus Emendatione Tratactus, proposing another way of reading Espinosa's first work.

\section{KEY WORDS}

Espinosa;

Tratactus de Intellectus Emendatione; Modern Philosophy. 
I.

Os estudiosos da obra de Espinosa não podem evitar as dificuldades suscitadas pelo Tratactus de Intellectus Emendatione ${ }^{1}$. Destas, as mais constantemente retomadas são o inacabamento do opúsculo e a apresentação das propriedades do intelecto logo após Espinosa haver afirmado que todo conhecimento verdadeiro parte de uma definição de essência e jamais das propriedades do objeto a ser conhecido. Ao lado dessas duas dificuldades principais, o tratado ainda apresenta algumas outras igualmente embaraçosas. Em primeiro lugar, seu prólogo ou os onze primeiros parágrafos, que nos enviam muito mais aos textos estoicos de consolaçáo da filosofia do que a obras metodológicas, embora a discussão do método seja o objeto dessa pequena obra, o que levou, durante muito tempo, à dúvida quanto à autoria, alguns comentadores julgando-o escrito pelo amigo de Espinosa, Lodewijk Meijer. Em segundo lugar, sua cronologia. Até pouco tempo, o De emendatione era considerado a segunda obra de Espinosa que, depois de haver escrito um tratado de feição neoplatônica, o Breve Tratado, teria, sob o impacto da leitura da obra de Descartes, escrito a Emenda do Intelecto. Todavia, estudos de filologia e trabalhos eruditos lançaram por terra essa suposição, mostrando que o De Emendatione é a primeira obra de Espinosa e que o prólogo é também de sua autoria ${ }^{2}$. Isso, no entanto, coloca um novo problema, qual seja, saber se se trata de um texto cartesiano sem continuidade na obra seguinte do filósofo, o Breve Tratado, ou se, como querem alguns, a feição cartesiana do texto tem como causa seus destinatários que, sendo cartesianos, entenderiam melhor o opúsculo se este fosse escrito numa linguagem com que estavam familiarizados ${ }^{3}$. Enfim, uma outra dificuldade que frequentemente vem à tona diz respeito ao súbito aparecimento, no texto, de problemas de filosofia natural ou sobre a cientificidade da física e o estatuto dos experimentos.

Curiosamente, a questão acerca do caráter cartesiano do tratado e das discussôes sobre a física acabaram por se transformar em instrumentos para explicar as duas primeiras dificuldades, isto é, o inacabamento da obra e a descrição das propriedades do intelecto. Os que defendem a feição cartesiana do opúsculo concluem que é exatamente esta a causa de seu inacabamento, isto é, Espinosa não poderia prosseguir porque, a partir de um determinado ponto, teria de expor sua própria filosofia e separar-se de Descartes ${ }^{4}$. Os que se voltam para a descrição das propriedades do intelecto julgam que o opúsculo permaneceu inacabado porque Espinosa deveria

\footnotetext{
1 Aqui será mencionado com a sigla conhecida TIE.

2 Cf. F. Akkermann, 1987; F. Mignini, 1979; P-F. Moreau, I994.

3 Cf. A. Mathéron, 1987.

4 É a posição de Mathéron, 1987.
} 
passar à gênese da essência do intelecto, o que só poderia ser feito pela Ética, de sorte que o final do De Emendatione deve conduzir-nos para fora dele e além dele, à obra magna do filósofo ${ }^{5}$. Finalmente, muitos julgam que a obra ficou inacabada porque Espinosa não dispunha dos elementos teóricos necessários para tratar da experiência e do experimento, tendo que interromper o texto ao chegar ao problema da constituição de uma física.

É nosso propósito, aqui, abandonar a tradição interpretativa, propondo uma outra maneira de ler a primeira obra de Espinosa.

II.

Depois que a experiência me ensinou que tudo o que acontece comumente na vida costumeira é vão e fútil, e vi que tudo que era para mim ocasião ou causa de medo não tinha em si nada de bom nem de mau, a não ser na medida em que nos comove o ânimo, decidi finalmente indagar se existia algo que fosse um bem verdadeiro, capaz de comunicar-se e, que rejeitados todos os outros, fosse o único a afetar o ânimo; algo quem uma vez descoberto e adquirido me desse a eterna fruição da suma e contínua alegria. (TIE $₫ \mathrm{I})$

Nessa abertura do tratado, quando o narrador descreve a dramática experiência de quem estava cativo na "comoção do ânimo" e a quem essa mesma experiência ensinou que "tudo na vida costumeira é vão e fútil", que coisa alguma "tinha em si nada de bom nem de mau", narra também a decisão que lhe foi inspirada por esse ensinamento: indagar se haveria um "bem verdadeiro, capaz de comunicar-se" e que, rejeitados todos os outros, "fosse o único a afetar o ânimo" com suprema e contínua alegria. Me tandem constituisse: "decidi-me, finalmente". O início é a stásis do meditante. Como tal, institui um começo, põe-se na melhor posição para o combate e a defesa, mantém-se com a firmeza do uma coluna ou de um pilar e colocase no ponto de nascimento ou de origem de uma ordem nova.

Decisão imprudente, à primeira vista, pois pareceria "deixar o certo pelo incerto". Decisão difícil: volvebam igitur animo, "revolvia, pois, o ânimo", conta o narrador, para ver se seria possível chegar a um novo modo de vida, novum institutum, "sem que se mudassem a ordem e a maneira de minha vida comum", ordo, et commune vitae meae institutum. Tentativa frustrada, frustra tentavi. Ao frustra tentavi contrapóe-se a decisão de mudar o foco da busca, indagando "o que seria mais útil" para a conservação de seu ser. É encontrada, assim, a boa stásis. O objeto da decisão é

5 É a posição de Lívio Teixeira, 1954. 
uma outra ordem de vida, uma ruptura na distração do ânimo, até então ocupado com bens vãos e fúteis.

Para a experiência, porque experientia vaga, errante e distraída, essa difícil decisão aparece primeiro como imprudência e, depois, como aporia porque se, por um lado, os bens que nos acontecem transformam-se continuamente em males, erguendo-se como obstáculo a uma nova ordem de vida, por outro lado, no entanto, parecem ser os únicos que ocorrem e acorrem aos homens e abandoná-los para procurar um outro há de aparecer como perigosa aposta em que se trocam bens certos por um bem incerto. Onde a aporia? $\mathrm{Na}$ oscilação do certo e do incerto: um bem que se transforma num mal, pode ser chamado bem? Mas um bem cuja incerteza pode custar-nos os que vemos na vida comum será um bem, se nos faz perder bens? Para o ânimo, a resolução parece aposta porque, na experiência, certo e incerto estão fora de ordem ou desordenados. À agitação do ânimo, o filósofo contrapóe uma outra experiência, a da "assídua meditação" na qual se descobre a diferença entre bens incertos por sua natureza, portanto males certos, e um bem incerto apenas quanto à possibilidade de alcançá-lo, portanto bem certo por sua natureza, pois imutável. Entre a multiplicidade concupiscente - bens no plural - e a unidade racional — bem no singular - há que apostar? A decisão não é uma aposta, como imaginaria o ânimo, mas a aquisição de duas certezas, alcançadas quando a meditação constante examina a natureza do que lhe é oferecido pela experiência. Ao focalizar noutra perspectiva bens e males, tomando o útil à conservação como medida da nova procura, a meditação descobre que "as coisas que o vulgo segue" são veneno e, assim, o meditante sabe que não tomou uma resoluçáo qualquer, mas decidiu entre a vida e a morte, "como um doente, atacado de fatal enfermidade, que antevê a morte certa se não encontra um remédio, é constrangido a procurá-lo com todas as suas forças." (\$7).

A abertura do De emendatione é a pintura dramática de uma experiência desordenada porque imersa nas coisas singulares mutáveis que parecem depender da fortuna - inexplicavelmente, bens e males acontecem aos homens, chegam a eles ou deles se afastam como se dirigidos por um poder estranho e caprichoso. Por isso, a emendatio é correção da desordem da vida comum por uma outra ordem de vida na qual até mesmo os vana et futilia irão se tornar úteis quando reordenados por um novum institutum. É preciso insistir que se trata de reordenação. De fato, ordo vitae communis e ordo vitae meae indicam que há uma ordem de vida comum; que essa ordem é instituída pelas maneiras como o ânimo é afetado pelas coisas exteriores que encontra, agarra e perde; que é marcada pela instabilidade porque determinada pela maneira fortuita com que adquirimos e perdemos os bens. Reordenar é buscar o caminho que conduz do encontro fortuito à descoberta deliberada de uma outra ordem, agora estável. A reordenação da vida sob a regra do útil é sobredeterminada 
por uma outra regra, qual seja, "que toda nossa felicidade e infelicidade dependem da qualidade do objeto ao qual nos unimos por amor", que determina qual o objeto útil ou o mais útil, "o amor das coisas eternas e infinitas". Essas duas regras esclarecem a sequência do texto, aparentemente paradoxal porque, para nosso espanto, Espinosa imediatamente afirma que "quando soubermos que tudo o que é feito acontece segundo uma ordem eterna e conforme leis certas da Natureza" (\$ I2) saberemos que bom e mau, assim como perfeito e imperfeito, não estão nas coisas, mas são relaçóes que dependem de nós. Dessa maneira, não só ordo parece deslocarse da nossa maneira de viver para a maneira de agir da Natureza ou suas "leis certas", mas também a ordo Naturae parece anular a ordo vitae meae porque nesta última bens e males fazem sentido, enquanto naquela parecem não merecer consideração. No entanto, não houve deslocamento algum, uma vez que a idéia de útil (o que favorece nossa auto-conservação), oferecendo à errância da experiência um rumo novo e constante, já havia inserido a ordem de vida na ordem da Natureza.

A idéia de ordem da Natureza é determinante para o sentido da nova ordem de vida, ambas sendo inseparáveis. É sobre esta articulação das duas ordens que vem assentar-se a ordem do conhecimento e esta pede o trabalho metódico da emenda do intelecto para que este se torne apto a concretizar a decisão tomada pelo meditante. O método, porque emendatio, é a verdadeira lógica no sentido que lhe dão os Seiscentos - purificação, separação, distinção entre imaginar e compreender -- e por isso Espinosa insiste em que ele é o caminho que nos ensina a proceder "na ordem devida" (debitus ordo).

Que é, pois, a emendatio? Passagem da ordem comum da Natureza (vita communis), na qual as existências aparecem na dependência de circunstâncias fortuitas que não nos dizem o que são suas essências singulares, à ordem necessária da Natureza (res fixae aeternaeque, novum institutum) na qual as essências singulares são deduzidas e concatenadas a todas as outras, evidenciando a ordem e conexão de suas existências. Emendatio é passar da desordem das existências mutáveis oferecidas à experiência à ordem necessária e imutável de dependência causal das essências conhecidas pelo intelecto; emendatio não é passar do mutável ao imutável, mas ao conhecimento das leis imutáveis da mudança. É passar do drama da aquisição e perda incessante do que desejamos ao conhecimento da potência causal do Ser Perfeitíssimo que determina a ordem de produção dos seres finitos existentes na duraçáo ou as leis que ordenam os seres submetidos à mudança. Emendatio é o acesso à ordem das existências pelo conhecimento de suas essências ordenandamente produzidas.

A emendatio não expulsa a experientia: apenas a ordena numa experiência que se sabe a si mesma. Com efeito, a experiência errante já era, à sua maneira, uma experiência docente, pois a perda incessante dos bens ou sua inversão em males indicava 
que algo na natureza das coisas desejadas as impedia de concretizar o desejo de felicidade ou de alegria contínua. Há, porém, um laço mais forte prendendo experiência e força intelectual. Que fazia a experiência errante? Vagueava de bem em bem, e na inconstância era constante: sempre buscava muitos bens, sempre desejava a diversidade de muitas coisas. Ora, quando Espinosa descreve a passagem da mente do "ser dirigida" ao "dirigir-se", afirma que, ao entender-se melhor a si mesma, a mente conhece mais coisas e quanto mais coisas conhece, mais conhece a ordem da Natureza inteira e mais se acerca da idéia que é o verdadeiro ponto de partida do conhecimento, a do Ser Perfeitíssimo. Vemos, assim, que o desejo errante de bens e o conhecimento verdadeiro das coisas possuem uma estrutura análoga (a busca do aumento) e que a diferença entre ambos encontra-se exatamente "na qualidade do objeto ao qual nos unimos por amor". Ao introduzir o útil como critério de avaliação dos bens e defini-lo pela auto-conservação, Espinosa desata o nó que prendia o desejo à diversidade concupiscente para atá-lo no laço que o prende à obra intelectual de conhecimento porque ambos, desejo e intelecto, são parentes, esforço de aumento de ser.

A emendatio explora duas determinaçóes encontradas no ânimo doente: $\mathrm{o}$ anseio pela pluralidade e o ideal de uma natureza humana mais perfeita. A subversão espinosana está em não oferecer ao doente um ideal normativo externo e teleológico, mas em fazê-lo descobrir em si mesmo a força inata para curar-se. Eis porque seu ponto de partida é o exame da "ordem que naturalmente temos" para conhecer, apresentando o que Espinosa denomina modos de percepçáo - conhecimento por ouvir dizer; experiência errante; dedução de uma causa a partir do efeito; conhecimento intuitivo da essência da coisa ou de sua causa. Ao começar pela "ordem que naturalmente temos", a emendatio visa separar a dispersão desordenada em que se encontra a experiência, dando-lhe uma coesão ordenada ao lhe mostrar qual multiplicidade lhe dará "alegria contínua", isto é, o conhecimento da ordem da Natureza inteira com a qual poderá unir-se. Mas não só isso. $\mathrm{O}$ percurso pelos modos de conhecer é exatamente o que Espinosa chama de método. Em outras palavras, o método não é um conjunto de regras para o bom conhecimento e si o conhecimento que a mente humana adquire de si mesma - o método é reflexivo e garantia da força inata da mente humana para curar a si mesma.

Dessa maneira, dispomos de uma indicaçáo precisa que nos permite recusar a tradição interpretativa que considera o De emendatione um texto aporético. De fato, a aporia se desfaz inteiramente se compreendermos que o De emendatione tem a estrutura de um tratado de medicina e que seu inacabamento (o célebre reliqua desiderantur) não é aporético. Como tratado de medicina, constrói um diagnóstico e propôe uma terapêutica. 
III.

No século XVII, a idéia de medicina animi não era nova: havia sido consagrada pelos tratados estóicos de vita beata e explicitamente afirmada como verdadeira definição da filosofia no Livro III das Tusculanas, depois de Cícero haver indagado com perplexidade como entender que, sendo compostos de corpo e ânimo, os homens tenham criado uma medicina para curar o primeiro, consagrando-a aos deuses imortais, mas tenham demorado tanto para inventar a medicina animi, que, depois de inventada, não foi cultivada e "não é grata nem aprovada, mas suspeita e odiosa para a maioria". E indaga ele: "Seria porque julgamos com o ânimo o mal do corpo enquanto pelo corpo não sentimos as doenças do ânimo?”. Não é grave permanecer inculta a medicina do ânimo quando sabemos que a alma julga a si mesma, e como poderá fazê-lo se "justamente aquilo com que julga está doente”? A medicina do ânimo é a filosofia. ${ }^{6}$

Entendida como purificação moral em vista de uma vida melhor, a filosofia como emendatio também não era uma idéia nova: encontrava-se nos textos antigos e cristãos de conversão da alma a Deus, tivera na Consolação da filosofia de Boécio e nas Confissóes de Agostinho sua realização paradigmática, na qual o superior julga o inferior e, por isso, a cura da razáo é conversáo da alma, preparada (em Boécio, pela Philosophia e, em Agostinho, pelo Mestre Interior) para receber a iluminação do Sumo Bem, deixando-a vazia e tendida para consumar o páthos cristão de recepção do Verbo. Entre os modernos, a idéia de cura do ânimo e da razão fora restituída pelo médico paduano, Nifo, com o De ratione medendi, e por Bacon, inspirado pela expurgatio praticada pelos alquimistas e pela dissecatio praticada pela anatomia ${ }^{7}$. $\mathrm{Na}$ perspectiva ciceroniana, paduana e baconiana, a medicina do ânimo era pedagógica; seu escopo era o cultivo do espírito.

${ }^{6}$ Cícero Tusculanae disputationes, III, i (I-3), iv (7). "Como podemos aceitar a noção de que o ânimo não pode curar-se a si mesmo (ut sibi mederi animus non possit) vendo que o ânimo inventou (animus invenerit) a própria arte de sarar o corpo e vendo que a constituição dos próprios homens, assim como a Natureza, contribuem em muito para a cura do corpo e que nem todos os que se submeteram a tratamentos rumam para a convalescença, enquanto vemos, ao contrário, que todos os ânimos que estiveram prontos para a cura e seguiram as instruçôes de homens sábios, estão indubitavelmente curados (sanetur)? Certamente, há uma arte para curar o ânimo. Quero dizer, a filosofia, cujo auxílio deve ser buscado não, como no caso da doença corporal, fora de nós mesmos [...], mas devemos esforçar-nos tanto quanto em nossas forças para seremos médicos de nós mesmos (nosmet ipsi nobis mederi).", iv (7).

7 A alquimia encarrega-se de separar (separare) e extrair (extrahere) o que está escondido e implicado nos corpos, procurando purificá-los (depurare), liberando-os de obstáculos, fazendo-os amadurecer, acelerando ou retardando seu movimento. Todavia, Bacon não é alquimista. Ainda que fale em antipatias e simpatias, que conceba o appetitus como natural a todos os seres, que empregue, no caso da alma, expressóes como expurgare, emendare, e, no caso do corpo, depurare, Bacon desenvolve uma concepção inteiramente artificialista da "separaçáo", cujo modelo é a dissectio, praticada pela anatomia, e cujo objeto é a Natureza atormentada. Artifício prudente e industrioso, a separação e a dissecção operam sobre as formas, tanto para transformá-las como para fazê-las gerar seres inesperados que a Natureza, deixada a si mesma, jamais engendraria. 
Sob essa longa e venerável tradição, a medicina animi, herdeira da medicina dos humores, não esconde sua origem estóico-romana: é um tratado das paixôes da alma, no qual a terapia dos humores se realiza por meio da retórica porque, desde Aristóteles, é ela a mestra e senhora dos pathémata. A essa tradição vem opor-se Descartes quando abre o Traité des passions de l'âme declarando que "o que os Antigos ensinaram é táo pouca coisa e a maior parte táo pouco crível", que náo pode haver "esperança de aproximar-se da verdade" senão afastando-se "dos caminhos que seguiram” (Descartes, Les passions de l'âme, AT, XI, p. 327-328). Esse afastamento é indicado desde o prefácio do Traité, assim como na Resposta à Segunda Carta de Egmont, quando Descartes explica que não falará como orador nem como filósofo moral, e sim como fisiólogo ou médico: mon dessein n'a pas esté d'expliquer les Passions en Orateur, ny mesme en Philosophe moral, mais seulement en Physien. (Ibid., p 326 ).

O "Prólogo" do De emendatione, isto é, seus onze parágrafos iniciais, parece devedor da literatura da medicina animi e também do Traité cartesiano. Da primeira, recebe a idéia da emendatio como mudança de vida, no embate entre a fortuna e o desejo do bem; do segundo, a perspectiva naturalista, que o libera da imagem religiosa da conversão como itinerário da alma a Deus por intermédio de uma intervenção sobrenatural. Todavia, há nesse "Prólogo" uma expressão que o afasta da literatura de vita beata e da fisiologia cartesiana. Diferentemente da primeira, Espinosa não fala em summum bonum, e sim em verum bonum (e quando, findo o "Prólogo", a idéia de sumo bem for proferida, estará na dependência da idéia de bem verdadeiro); diferentemente da segunda, Espinosa não se ocupa, como fará na Ética, com as relaçóes entre a alma e o corpo (ainda que, ao se referir à memória e à linguagem, não deixe de mencionar que, sendo devedoras da imaginação, são por isso devedoras do corpo). Ao introduzir o verum para determinar o bonum, o De emendatione assenta a medicina animi sobre a teoria do conhecimento.

Lidos à luz da tradição médica, os onze primeiros parágrafos do De emendatione deixam ver que seguem a preceptiva quinhentista e seiscentista do tratado de medicina, e, após o "Prólogo", a exposição do método, na seqüência do texto, acompanha os preceitos de composição de um moderno tratado de anatomia.

O texto se abre com a afirmaçáo de que a experiência é ensinante: dela nos vem o conhecimento do lugar da fortuna nos acontecimentos humanos, fazendo da ordo vitae communis um círculo no qual a concupiscência, desejo insaciável de diversidade, é alimentada pela fortuna, cornucópia de bens e males que caem sobre nós e que, vindos e idos ao acaso, preenchem e esvaziam o desejo, que não pode cessar de buscá-los para perdê-los e perder-se neles. A descrição dramática do estado de ânimo daquele que é objeto de divertimento para os caprichos da fortuna recolhe da experiência um segundo ensinamento: o ânimo está doente. Tanto o relato da vita 
communis como o diagnóstico da enfermidade se realizam no campo próprio do trabalho do médico, isto é, de uma experiência que não pode afastar o acaso e a incerteza, mas que, por isso mesmo, ensina que é preciso agarrar o momento que acontece, a occasio, e seu oportuno instante fugidio, o kairós. $\mathrm{O}$ momento oportuno para o médico, dissera a tradição hipocrática, é a crise, e é ela que o filósofo descreve quando, no $\$ 7$, escreve:

Sentia, assim, encontrar-me em extremo perigo e ter de procurar, com todas as minhas forças, um remédio, ainda que incerto; como um doente que, atacado de fatal enfermidade, antevê morte certa se não encontra um remédio, é constrangido a procurá-lo com todas as suas forças, mesmo que ele seja incerto, porque nele está sua única esperança.

Os onze primeiros parágrafos são, assim, a abertura hipocrática do Tratado: diagnosticam a doença do ânimo como desordem vital, oferecem a etiologia dessa doença (o jogo mortal entre concupiscência e fortuna), apontam o início da cura com a busca do remédio, ainda que incerto, no momento do ataque agudo (o ataque de uma enfermidade que se tornou fatal) que exige o juízo (krisis) ou a tomada de posição (me tandem constituisse) que instaura o caminho e a via da saúde, o methodus, isto é, a arte que se opóe ao acaso (passar da "ordem que naturalmente temos" à "ordem devida para filosofar").

Nesses parágrafos iniciais, encontramos a resposta de Espinosa ao amigo médico, Bouwmeester, que lhe perguntara se "pode haver um método que nos permita avançar com toda segurança na reflexão dos mais difíceis problemas", ou se, ao contrário, nosso intelecto, "como nosso corpo, está submetido ao acaso, nossos pensamentos regidos antes pela fortuna do que pela arte?”. A indagaçáo (ciceroniana) de Bouwmeester é a de quem, com a tradição hipocrática, jamais esqueceu o primeiro dos Aforismas do Corpus hippocraticus a lhe dizer que "a vida é breve; a arte, longa; o momento oportuno, raro; a experiência, traidora; e o juízo, difícil”. À interrogação do amigo, Espinosa respondera que pode haver um método que nos mostre como encadear necessariamente nossos pensamentos claros e distintos para que "o intelecto, diferentemente do corpo, não fique submetido ao acaso”. Mas não só isso. Espinosa escrevera ao amigo dizendo-lhe que, para o método, basta fazer "à maneira de Verulâmio", isto é, apresentar uma historiolam mentis. Essa historiolam é a enumeração dos quatro modos de conhecer ou os quatro modos de percepçáo. Essa enumeração é apresentada por Espinosa em conformidade com aquilo que os tratados de medicina designavam como historia.

Eis por que, terminado o "Prólogo", isto é, feito o diagnóstico e tomada a decisão de curar-se, o Tratactus segue os passos de um tratado de medicina, propondo por 
isso a seqüência com que trabalha o médico quando estuda a anatomia e a fisiologia, classifica as patologias e propóe uma terapêutica: historia, actio, usus e utilitas das "partes". No caso do De emendatione essa seqüência se realiza como descrição, operação e função da mente humana. Historia: descrição da mente segundo "a ordem que naturalmente temos", de maneira a distinguir intelecto e imaginação. Actio: as operaçóes que a mente realiza — modos de percepção, idéias fictícias, falsas, duvidosas e verdadeiras. Usus ou utilitas: discriminação dos modos de percepçáo, conforme sejam modos da imaginaçáo ou do intelecto, determinaçáo do melhor (o quarto modo de percepção é aquele no qual há o uso pleno do intelecto). Patologia: o ânimo doente é aquele no qual intelecto e imaginação, cujos usos são diferentes, estão mesclados e confundidos sem que nenhum deles realize sua função própria. Terapêutica: determinar o melhor uso do intelecto e a melhor maneira de usá-lo (teoria da definição perfeita), possibilitando o retorno saudável à experiência, agora como experiência ordenada e regulada pelo intelecto, isto é, como experimento.

Os paduanos, mestres de medicina e anatomia, consideravam que a passagem da historia à scientia se dava não só quando, da primeira, inferia-se a causa, isto é, pela demonstração ratione quia, a historia permitia o conhecimento da actio e do usus, mas sobretudo quando, pela articulação entre a historia e o conhecimento causal da actio (causa eficiente) e do usus (causa final), podia-se demonstrar propter quid a própria historia. Ou seja, a operação descritiva da historia se tornava objeto de conhecimento demonstrativo, graças à dimensão causal da actio e do usus. Essa estrutura discursiva é mantida pelo De emendatione, que, exatamente por isso, após oferecer a historia, a actio e o usus da mente, introduz, como o anatomista e o filósofo natural, o adágio dos antigos, "conhecer é conhecer pela causa". No entanto, é também nesse preciso momento que o texto espinosano rompe com a tradiçáo da filosofia natural e a diferença entre ele e a tradição médica quinhentista se torna manifesta.

De fato, para Zabarella, a natura era não só a essência da coisa, mas também uma facultas, isto é, propensão interna ou inclinatio para mudar, faculdade apta a realizar sempre apenas um dos termos de uma oposição e, sob este aspecto, oposta ao animus que, por ser livre, era capaz dos possíveis contrários. Disso resultava a distinção entre facultas (própria a uma natura) e habitus (ou a ação da voluntas). Uma natura realizase segundo a necessidade inscrita nas potencialidades de sua matéria e segundo as propensóes ou inclinaçóes a que sua matéria a dispóe; e por sua aptidão a receber movimentos segundo as determinaçóes de sua forma. A natura era, assim, o princípio passivo ou a faculdade para um único movimento determinado por sua matéria e por sua forma, enquanto a voluntas era um princípio ativo agindo em função de causas finais.

A ruptura espinosana aparece, antes de tudo, quando a agitação do ânimo, afetado por afecçóes contrárias que o fazem oscilar entre elas, não mais é atribuída à 
liberdade da vontade, e sim à necessidade da natureza do próprio ânimo. A ruptura prossegue com a retomada do adágio tradicional - "conhecer é conhecer pela causa" - , acompanhado, porém, da declaração de que ninguém, até então, concebera que a causa é o próprio intelecto agindo como autômato espiritual, portanto, como causa eficiente interna que exclui toda referência a qualquer causalidade final. Por isso mesmo, a natura do intelecto o faz ser causa ou força inata (vis nativa), cujo primeiro e exemplar efeito ou, antes, cuja actio e cujo usus deixam-se conhecer melhor no exercício da matemática e não no da filosofia natural.

Em outras palavras, ao introduzir o adágio aristotélico-paduano scire, per causas scire, o engenho do De emendatione consiste em afastar as causas tais como pensadas pela tradiçáo naturalista e por isso coloca-se na clave de um meta-discurso que, ao fazer do objeto do discurso, isto é, do intelecto, a causa do conhecimento verdadeiro, torna-se capaz de explicar por que há ciência matemática, por que nela a actio e o usus do intelecto melhor se evidenciam, e sob que condiçóes pode haver filosofia natural ou ciência experimental, isto é, experiência ordenada e regulada pelo intelecto. É esse um momento decisivo da emendatio, pois a cura do intelecto envolve a reforma de todo o saber instituído. Em outras palavras, o percurso reflexivo do intelecto deve também ser lido como uma epistemologia. Assim, é preciso reunir o me tandem constituisse e o novum institutum - isto é, o tomar posição para instituir uma vida nova - à emendatio intellectus, para que se possa perceber que esta última, ao encontrar a melhor actio e o melhor usus da experientia, incide não só sobre a ética, mas também sobre todo o campo do saber estabelecido pela filosofia natural, sem o que náo poderíamos apreender o sentido da exigência que permeia o De emendatione, qual seja, passar da "ordem que naturalmente temos" à "ordem devida para filosofar".

Como tratado médico-anatômico e terapêutico, o De emendatione possui uma estrutura discursiva na qual devem tornar-se inteligíveis a própria idéia de método e as partes de sua exposição: para adquirir o método, é preciso emendar o intelecto, e essa emenda já é o primeiro momento do próprio método, pois somente agindo e exercitando-se a si mesmo pode o intelecto curar-se, isto é, adquirir o conhecimento de sua força natural e saber o que é uma idéia verdadeira.

Essa "Lição de Anatomia" tem a peculiaridade de não ser uma dissecação do morto, e sim a autovivisseçáo do intelecto para a descobrir a cura do ânimo doente, na mais perfeita consonância com o dito socrático e ciceroniano, tão caro a Montaigne, do filósofo como médico de si mesmo. Como medicina de si mesmo, o método diagnostica a doença - a agitação do ânimo decorre da confusão entre imaginação e intelecto e propóe sua primeira parte, qual seja, distinguir e separar o imaginar e o compreender; em seguida, na sua segunda parte, póe-se a conhecer a força do intelecto e propóe regras de pensamento deduzidas do próprio exercício intelectual. 
Espinosa náo deixa inacabado o Tratado porque sua sequência necessária deve ser a Ética, mas porque, como explica a seu amigo Tschirnhaus, ainda "não coloquei por escrito minha física" e, portanto, sua teoria da relação entre demonstração geométrica e experimento, de sorte que a sequência do De Emendatione, respeitando a coerência do gênero literário escolhido (um tratado), de seu objeto (a experiência) e de sua estrutura (um tratado médico-anatômico), deveria concluir-se com uma descrição metódica do experimento para a qual, como dissera a Tschirnhaus, precisaria de mais tempo de vida...

\section{Bibliografia}

Spinoza (1925). Opera. Carl Gebhardt (org). Por ordem da Heidelberger Akademie des Wissenschaften, 4 vols. Heidelberg: Carl Winter,

Akkermann, F. (1980). Studies in the Posthumous Works of Spinoza. On style, earliest translations and reception, earliest and modern edition of some texts. Groningen: Rijksuniversiteit Groningen.

Akkermann, F. (1987). "La latinité de Spinoza et l'authenticité du texte du Tratactus de intellectus emendatione", in: Revue des Sciences Philoso-hiques et Théokogiques, vol.7, n.I.

Mignini, F. (1979). "Per la datazione e l'interpretazione dello Tratactus de intellectus emendatione di Spinoza, in: La Cultura, n. I7.

Moreau, P.-F. (1994). Spinoza. L'expérience et l'éternité, Paris: PUF.

Mathéron, A. (1987). "Pourquoi le Tratactus de intellectus emendatione est-il resté inachevé?", in: Revue des Sciences Philosophiques et Théologiques, n. 7I.

Teixeira, L. (1954). "A Doutrina dos modos de percepção e o problema da abstração na filosofia de Espinosa”, in: Boletim 54. São Paulo: Faculdade de Filosofia, Ciências e Letras da Universidade de São Paulo. 